ARTIFICIAL FEVER.

By Clarence A. Neymann, A.B., M.D., F.R.S.M. Baillière, Tindall \& Cox, London. 1938. Price 27/-.

Dr. Clarence Neymann's name is well known to psychiatrists all over the world, and in particular his name has been associated with the treatment of general paralysis of the insane or dementia paralytica by means of artificially produced fever.

In his most recent book "Artificial Fever" he has made a complete re-exposition of his experiences since he started his first serious efforts at producing fever in 1927.

The book is complete. Commencing with basic theories and principles he deals with the physiology of hyperpyrexia very thoroughly, and complete laboratory findings are published.

The next chapter deals with the technique of the procedure, both from the medical and the electrical angle, and his results and technical variations in dealing with cases of dementia paralytica, syphilis of the central nervous system, multiple sclerosis, chorea minor, arthritis, gonorrhœa and asthma form the subject matter of the following chapters.

In the last chapter labelled " Dreams and Facts " he considers the survival of man, the acquired characteristics developed over a million years, and the dreams he has envisaged as the result of his experience of electropyrexia.

The book bristles with that thoroughness which is so characteristic of American work, and is thoroughly interesting. The enthusiasm with which it is written is infectious and one puts it down at the end with a feeling that electropyrexia must represent the millenium of medicine.

It is unfortunate that in this country we have not developed the technique and its applications to anything like the same extent.

The so-called " sweating" diathermy is of course an elementary application of the principle and is used a good deal here, but as Dr. Neymann himself says, the machines used for electropyrexia are being improved each year, and he has entirely given up the older methods of medium wave diathermy and now only uses electro-magnetic induction.
The advantages of this method are numerous, the most obvious being that diathermy " burns" are practically done away with. Dr. Neymann combines this method with an air conditioned cabinet and with this double weapon is able to induce pyrexia up to a practically unlimited extent for many hours. The intensity and prolongation of his therapy is undoubtedly responsible for his very excellent results. $\mathrm{He}$ has produced temperature curves ranging between $103.5^{\circ} \mathrm{F}$. and $108.5^{\circ} \mathrm{F}$. lasting for fifteen hours.

In order to check his results he has had special thermocouples made for insertion into the cisterna magna, the lumbar spinal cord, and under the skin, and a simultaneous pyrometer record is kept of the axillary and rectal temperatures.

Perhaps the most interesting chapter in the book deals with multiple sclerosis, generally called here disseminated sclerosis. Dr. Neymann's view is that a patient once bedridden will never walk again, and that the treatment of this disease demands greater care than any other disease, respiratory failure or acute dyspnœea being the greatest danger. Nevertheless he feels that electropyrexia has a definite use, and in a series of 25 cases he finds 44 per cent. much improved and 40 per cent. improved. Remissions after this treatment are more frequent and last longer than untreated cases and he feels, perhaps justly, that if all remissions are regarded as potential natural remissions the outlook in the disease becomes too pessimistic.

This book is one which should be read and owned by everyone interested in neurology or in physical medicine for it represents the up-to-date view of electropyrexia, and leaves the reader, from facts supplied, to form his own opinion of the method. And no book can do more than this.

\section{HEALTH AND FITNESS.}

By Ethel Browning, M.D. Rich \& Cowan, London. 1938. Price 3/6.

This book is divided into general principles of health, diet and mental health. The remainder of the book is devoted to special considerations appertaining to the various ages, school, adolescence, adult life and old age. 
It is a very sensible little book putting into plain English the sort of ideas that every doctor would desire to inculcate into his patients.

\section{TREATMENT BY DIET.}

By Clifford J. Barborka, B.S., M.S., M.D., D.Sc., F.A.C.P. Third edition. J. P. Lippincott Company, London and Philadelphia. 1938. Price 21/-.

Three editions of this book have been called for in four years and this by itself should be sufficient evidence of its popularity, and of the need for such a book. And, indeed, this is not to be wondered at, for the book is the most complete of its sort, and the author makes every effort to keep it up to date.
It seems that a useful purpose would have been served by still further elaborating the recently added chapter on clinical aspects of the vitamins for although good it gives a very sketchy idea of the present position.

The vitamin C. section, however, mentions the three methods of determining whether this vitamin is present in adequate quantity in the body, and mentions simple tests for its recognition but says nothing of the probable importance of this vitamin in infections.

All the usual diets are shown, and acid and alkaline-ash diets are mentioned. The chapter on obesity has been enlarged and a note on Protamine zinc insulinate has been added.

A very good book, very well printed and very easy to read.

\section{AFFILIATED SOCIETY.}

\section{SUTTON \& DISTRICT MEDICAL SOCIETY (Season 1938-1939).}

Friday, December 2nd.

\section{CRESSY MEMORIAL LECTURE.}

Lecturer: Sir Lancelot Barrington-Ward, K.C.V.O., F.R.C.S.

" Gallstones--Ten Years' Surgical Experience."

Friday, December 16th.

\section{AT SUTTON HOSPITAL.}

Demonstrations, etc., in the Pathological Department, arranged by Dr. Hughes.

Exhibition of Photographs, etc., in the X-Ray Department, arranged by Dr. Rae.

Friday, January 13th.

Speaker: Dr. I. Jones, M.R.C.P.

"Some Sidelights of Medical Interest at Scotland Yard."

FrIDAy, February 3rd.

Speaker: Dr. Alan Moncrieff, F.R.C.P.

"Wasting or Marasmus."

FrIDAY, MARCH 3rd.

Speaker: Dr. H. Yellowlees, O.B.E., F.R.C.P.

"Anxiety States."

FrIDAY, MARCH 31st.

Speaker: Dr. C. Langton Hewer, D.A.

"Modern Anæsthesia."

FrIDAY, MaY 5th.

ANNUAL DINNER, 7.45 for 8 p.m. The visiting speakers will be guests of the Society.

Meetings are held at 8.30 for 8.45 sharp at The "Greyhound " Hotel, Carshalton. "Greyhound "'Phone: Wallington 1511. 